\title{
İlahiyat Fakültesi Öğrencilerinin Nomofobi Düzeylerinin Çeşitli Faktörler Açısından İncelenmesi
}

DOI: $10.26466 /$ opus. 461523

\section{$\underline{\text { Emine Zehra Turan* }}^{*}$ - Gökçe Becit İşçitürk}

* Dr., Öğr. Üyesi. Nevşehir Hacı Bektaş Veli Üniversitesi, İlahiyat Fakültesi, Nevşehir / Türkiye E-Posta: zturan@nevsehir.edu.tr

ORCID: 0000-0001-5635-0032

*Dr., Öğr. Üyesi. Nevşehir Hacı Bektaş Veli Üniversitesi, Eğitim Fakültesi, Nevşehir / Türkiye

E-Posta: gokcebi@nevsehir.edu.tr

ORCID: 0000-0001-6375-342X

\section{Öz}

Bu araştırmada, akıllı telefonlardan yoksun kalma korkusu olarak bilinen nomofobi kavramının İlahiyat Fakültesi öğrencileri arasındaki yaygınlığının incelenmesi amaçlanmıştır. Bu amaç doğrultusunda nicel ve nitel veriler nicel verileri elde etmek için araştırmanın alt amaçları; i) Öğrencilerin nomofobi düzeyleri nedir? ii) Öğrencilerin nomofobi ölçeğinin alt boyutlarına ilişkin ortalamaları nasıldır? iii) Öğrencilerin nomofobi düzeyleri cinsiyete göre anlamlı bir farklllı göstermekte midir? Araştırmada, analiz tekniği olarak hem nicel hem nitel boyutlar içeren karma yöntem kullanılmıştır. Araştırma, Nevşehir Hacı Bektaş Veli Üniversitesi İlahiyat Fakültesi öğrencilerinin gönüllü katılımı ile gerçekleştirilmiştir. Araştırmanın verileri, Yıldırım ve Correia (2015) tarafından geliştirilen ve Yıldırım, Şumuer, Adnan ve Yıldırım (2016) tarafından Türkçeye uyarlanmış Nomofobi ölçeği (NMP-Q), demografik bilgi formu ve nitel yar yapılandırılmış görüşme formu aracılığıyla toplanmıştır. Araştırmanın nicel boyutunda 276 öğrenciye ulaşılmıştır. Katılımcıların 172'si kadın (\%62,3), 104'ü erkektir (\%37,7). Araştırmanın nitel boyutu için, nicel boyuta katılan öğrencilerden 20'si rastsal olarak seçilmiş ve görüşmeler yapılmıştır. Toplanan nitel veriler betimsel istatistikler ile, nicel veriler ise bağımsız örneklem $t$-testi, tek yönlü varyans analizi(ANOVA) ile analiz edilmiştir.

Anahtar Kelimeler: Nomofobi, İlahiyat Fakültesi, akıllı telefon

OPUS @ C Uluslararası Toplum Araştırmaları Dergisi-International Journal of Society Researches ISSN:2528-9527 E-ISSN : 2528-9535

http://opusjournal.net 


\title{
The Investigation about Nomofobi Levels of the Students of Theology Faculty in Terms of Various Factors
}

\begin{abstract}
In this study, it is aimed to examine the prevalence of nomophobia, which is known as fear of lack of smart phones, among the students of the Faculty of Theology. For this purpose, quantitative and qualitative data obtained from the sub-objectives of the research data; i) What are the students' nomophobia levels? ii) What are the students' mean scores on the sub-dimensions of the nomophobia scale? iii) Do the students' nomophobia levels differ significantly by gender? In the research, mixed method including quantitative and qualitative dimensions was used as analysis technique. The research was carried out with voluntary participation of the students of the Faculty of Theology of Nevşehir Hacı Bektaş Veli University. For the purpose of the study, the data was collected trough a scale made by Yildirim and Correia (2015) and adapted to Turkish by Yildirim, Shumuer, Adnan and Yildirim (2016) based on the Nomophobia scale (NMP-Q), demographic information form and qualitative semi-structured interview form. In the quantitative dimension of the study, 276 students were reached. 172 of the participants were female (62.3\%) and 104 were male (37.7\%). For the qualitative dimension of the study, 20 of the students who participated in the quantitative dimension were randomly selected and interviews were conducted.
\end{abstract}

Keywords: Nomofobi, Faculty of Theology, smart phone

OPUS (c) Uluslararası Toplum Araştırmaları Dergisi-International Journal of Society Researches ISSN:2528-9527 E-ISSN : 2528-9535

http://opusjournal.net 


\section{Giriş}

Bilgi çağı ile birlikte hayatımıza giren bilgi iletişim teknolojilerinde yaşanan hızlı değişimler gündelik yaşantılarımızı da etkilemektedir. İlk zamanlarda sadece sesli- yazılı olarak iletişim amacıyla kullanılan telefonlar süreç içerisinde fotoğraf çekme, internete bağlanma, iletişim kurma, alışveriş yapma gibi birçok özelliği ile akıllı telefonlara dönüşmüş ve yaygın olarak kullanılan bilgi iletişim teknolojilerinden biri olmuştur. Türkiye İstatistik Kurumu (TUIK, 2017) verilerine göre hanelerde taşınabilir bilgisayar (dizüstü, tablet, netbook vb.) bulunma oranının 2004 y1lında \%0,9 iken daha sonraki yıllarda sürekli bir artış göstererek 2017 yılında \%49,8 olduğu; hanelerde cep telefonu/akıllı telefon bulunma oranının 2004 yılında \%53,7 iken 2017 yılında \%97,8'e yükseldiği görülmektedir. Akıllı telefonlar aile bireylerini ve arkadaşları aramak, mesajlaşmak, her koşulda ve her anda onlarla bağlantıda olmak ve kalmak, internete bağlanmak, oyun oynamak ve müzik dinlemek, kısaca güzel vakit geçirmek için mecburi bir araç haline dönüşmüştür (Sar ve Işıklar, 2012). İletişim aracı olmaktan çok iletişim halinde kalma aracına dönüşen telefonlarla ilişkiler kontrol altında tutulmadıkça beraberinde bazı sıkıntılar getirmektedirler. Teknolojinin hızla yayılması ile birlikte bu tarz yanlış kullanımlar için farklı isimler bulunmuştur. İnternet bağımlılı̆̆ı, sosyal medya bağımlılığı ya da bilgisayar oyunları bağımlılığı gibi problemli internet kullanımı yanında internetsiz kalma korkusu (netlessphobia), nomofobi (nomophobia) ve günlük gelişmeleri kaçırma korkusu gibi yeni yeni tanımlanmaya ve tanılanmaya başlayan olgular gelmektedir (Öztürk, 2015).

Akıllı telefon kullanımı fiziksel olarak, göz sağlığına ve eklem rahatsızlıklarına ve kamburluğa, ruhsal olarak ise bağımlılık, stres, huzursuzluk etrafa yabancılaştırmakta, adeta robotlaştırmakta, hafizayı zayıflatmakta gibi olumsuz psikolojik etkilere neden olduğu bilinmektedir. Bir akıllı telefonu düzenli olarak yanında bulundurmak ve akıllı telefon ile fazlaca zaman geçirmek, yanında sarj aleti ya da yedek batarya taşımak, telefonunu kaybetme ya da yakınları ile iletişim kuramama, sarjının ya da kontörünün bitmesi durumlarında sinirli ve gergin hissetmek, düzenli olarak ekrana bakarak mesaj ya da arama olup olmadığını kontrol etmek, telefonunu sürekli açı tutmak, akıllı telefon için fazla para harca- 
mak gibi davranışlar nomofobinin klinik göstergeleri arasında yer almaktadır (Billieux, Van der Linden ve Rochat, 2008).

Türkiye'de genç yaş grubunun özellikle de üniversite öğrencilerinin nomofobi düzeyleri ve nomofobi düzeylerinin etkilendiği değişkenler üzerine çalışmalar bulunmaktadır. Adnan ve Gezgin (2016) tarafından üniversite öğrencileri ile yapılan çalışmada öğrencilerin nomofobi düzeylerinin ortalamanın üzerinde çıktığı tespit edilmiştir. Erdem, Kalkın, Türen ve Deniz (2016) tarafından yapılan araştırmanın sonuçlarına göre öğrencilerin \%55'inin nomofobik olduğu ve günde ortalama 6,43 saat akıllı telefonla zaman geçirdikleri; öğrencilerin nomofobik olma seviyesi ile günlük akıllı telefon kullanım sürelerinin pozitif yönlü, akademik başarıları ise negatif yönlü ilişkili olduğu sonucuna ulaşılmıştır. Burucuoğlu (2017) tarafından meslek yüksek okulu öğrencileri ile gerçekleştirilen bir diğer çalı̧̧mada da önlisans öğrencilerinin nomofobi düzeylerinin ortalamanın üstünde olduğu ve kadın ve erkek bireyler arasında nomofobi düzeyleri açısından anlamlı farklılıklar bulunduğu sonucuna ulaşılmıştır. Gezgin, Şumuer, Arslan ve Yıldırım (2017) tarafından yapılan çalışmada öğretmen adayları arasında nomofobinin yaygınlığını incelenmiş, öğretmen adaylarının nomofobi düzeylerinin ortalamanın üzerinde olduğu ve iletişim kaybı ve bilgiye erişememe konusunda öğretmen adaylarının endişe duyduğu tespit edilmiştir.

Bilgi iletişim teknolojilerinde yaşanan gelişmeler hayatlarımızı olumlu olduğu kadar olumsuz yönde de şekillendirebilmektedir. Bu bağlamda ortaya çıan nomofobi kavramının genç nüfus arasındaki yaygınlığ1nın incelendiği çalışmalar önem kazanmaktadır. Bu çalışmada nomofobi kavramının İlahiyat Fakültesi öğrencileri arasındaki yaygınlığının incelenmesi amaçlanmıştır. Bu amaç doğrultusunda nicel verileri elde etmek için araştırmanın alt amaçları;

1. Öğrencilerin nomofobi düzeyleri nedir?

2. Öğrencilerin nomofobi ölçeğinin alt boyutlarına ilişkin ortalamaları nasıldır?

3. Öğrencilerin nomofobi düzeyleri cinsiyete göre anlamlı bir farklılık göstermekte midir?

Ayrıca, nitel verileri ortaya koymak için yarı yapılandırılmış görüşme formunda şu sorulara cevap aranmıştır: 
1. Uzun süre telefonunuza bakmadığınızda bir rahatsızlık hisseder misiniz? Niçin?

2. Telefonunuzun şarjının bitmesi sizi rahatsız eder mi? Neden?

3. İnternet kotanızın ya da tl'lerinizin (kontörünüzün) bitmesi sizi rahatsız eder mi? Niçin?

4. Ailenize ya da arkadaşlarınıza ulaşamamak sizi rahatsız eder mi? Neden?

5. Ailenizin ya da arkadaşlarınızın size hemen ulaşamayacak olması fikri sizi rahatsız eder mi? Niçin?

6. Sosyal medya ya da diğer ağlara istediğiniz anda bağlanamamak sizi rahatsız eder mi? Niçin?

7. Çevrimiçi olamamak sizi rahatsız eder mi? Niçin?

\section{Yöntem}

\section{Araştırmanın Örneklemi}

$\mathrm{Bu}$ araştırmanın örneklemini Nevşehir Hacı Bektaş Veli Üniversitesi İlahiyat Fakültesi'nde öğrenim gören öğrenciler oluşturmaktadır. Araştırmada kullanılan ölçme araçları 2017-2018 Eğitim Öğretim yılı bahar yarı yılında uygulanmıştır. Kolayda örnekleme yöntemiyle 276 öğrenciye ulaşılmıştır. Katılımcıların 172'si kadın (\%62,3), 104'ü erkektir $(\% 37,7)$. Araştırmanın nitel boyutu için, nicel boyuta katılan öğrencilerden 20'si rastsal olarak seçilmiş ve görüşmeler yapılmıştır.

\section{Veri Toplama Yöntemi}

Araştırmada, analiz tekniği olarak hem nicel hem nitel boyutları içeren karma yöntem kullanılmıştır. Çalışmada önce nicel veriler, ardından nitel veriler toplanmıştır.

Karma desenlerden ise nicel verilerle, nitel veriler çözümlenip ilişkilendirileceği için yakınsayan paralel desen kullanılmıştır. Nicel ve nitel aşamaları araştırma sürecinin aynı olan bir aşamasında eş zamanlı olarak uygulanmasıyla oluşur. Bu desen yöntemlere eşit öncelik verir, çözüm- 
leme sırasında bu aşamaları birbirinden ayrı tutar ve daha sonra genel yorumlama yaparken sonuçları birleştirir (Creswell \& Clark, 2015; s122).

Nicel boyutta ölçek tekniği, nitel boyutta ise yarı yapılandırılmış grup görüşmesi tekniği kullanılmıştır. Creswell'e (2008) göre karma yöntem araştırmalarının temel kullanımı, nitel ve nicel araştırma yöntemlerinin birlikte veya harmanlanarak kullanılmasının araştırma problem ve sorularının bu yöntemlerin ayrı kullanılmasından daha iyi anlaşılmasını sağlamaktadır (Creswell \& Clark, 2015; s122).

Nicel Boyut: Araştırmada ölçme aracı olarak Yıldırım ve Correia (2015) tarafından geliştirilen ve Yıldırım, Sumuer, Adnan ve Yıldırım (2015) tarafından Türkçeye uyarlanan Nomofobi Ölçeği (NMP-Q) kullanılmıştır. Ölçek gerekli izinler alındıktan sonra öğrencilere açıklama yapılarak uygulanmıştır. Kolayda örnekleme yöntemiyle 276 öğrenciye ulaşılmıştır.

Nomofobi Ölçeği (NMP-Q): $\quad$ 7'li Likert tipinde (1: Kesinlikle Katılmıyorum, 7: Kesinlikle Katılıyorum) toplam 20 maddeden oluşmaktadır. 7'li likert ile ölçülen ve 20 ifadenin yer aldığı ölçekten alınabilecek minimum puan 20 maksimum puan 140'tır. 0-20 puan aralığ 1 nomofobinin olmadığını, 21-60 puan aralığı düşük düzeyde nomofobi, 61-100 puan aralığı orta düzey nomofobi, 101-140 puan aralığı yüksek düzeyde nomofobi olduğunu göstermektedir. Orijinal ölçeğin Cronbach's alpha kullanılarak hesaplanan güvenirlik katsayısı .95 ve Türkçe'ye uyarlanmış ölçeğin güvenirlik katsayısı ise .92 olarak verilmiştir. Ölçeğin dört alt boyutu bulunmaktadır: Bilgiye Erişememe (4 madde), Bağlantıyı Kaybetme (5 madde), İletişime Geçememe (6 madde) ve Rahat Hissedememe (5 madde). Orijinal ölçekte bu alt boyutların güvenirlik katsayıları sırasıyla. 94, .87, .83 ve. 81 olarak verilmiştir. Ölçeğin Türkçeye uyarlanmış hali için alt boyutların güvenirlik katsayıları ise sırasıyla $90, .74, .94$ ve. 91 olarak raporlanmıştır.

Nitel Boyut: Araştırmanın nitel boyutunda nitel araştırma yöntemlerinden durum çalışması, tarama modeli olarak ise odak grup görüşmesi yöntemi kullanılmıştır. Durum çalışması nitel araştırmada çok yaygın olarak kullanılan bir yaklaşımdır (Yıldırım ve Şimşek, 2005). 
Araştırmada veri toplama aracı olarak araştırmacılar tarafından hazırlanmış yarı yapılandırılmış açık uçlu sorulardan oluşan bir görüşme formu kullanılmıştır. Görüşme, araştırmaya katılan bireylerin belli bir konuda duygu ve düşüncelerini anlatma tekniği olarak tanımlanır (Yıldırım ve Şimşek, 2008, 120). Yarı yapılandırılmış görüşme tekniğinde araştırmacı önceden sormayı planladığı soruları hazırlar, aynı zamanda araştırmacı görüşmenin durumuna göre, daha başka alt sorularla görüşmenin akışını etkileyebilmektedir (Türnüklü, 2000, 6). Araştırmanın nitel verilerinin toplanması sürecinde çalışma grubu, İlahiyat Fakültesinde öğrenim gören ve nicel verilerinin toplandığ1 örneklemde bulunan, görüşmelere katılabileceğini belirten öğrencilerdir. Görüşmelerde 9 kadın ve 6 erkek öğrenci, toplamda 15 kişi yer almıştır.

\section{Verilerin Analizi}

Nicel Boyut: Nicel araştırma tekniklerine göre, uygulanan ölçekler, bilgisayarda SPSS'in 21,0 versiyonunda kodlanmış ve analiz edilmiştir. Değerlendirmelerde anlamlılık düzeyi .05 olarak benimsenmiştir. Araştırmada elde edilen verilerin çözümlenmesi amacıyla, aritmetik ortalama, standart sapma, yüzde, t-testi ve Tek Yönlü Varyans Analizi testleri yapılmıştır.

Nitel Boyut: Görüşmelerden elde edilen veriler çözümlemeler yapılarak içerik analiz için hazır hale getirilmiştir. Nitel verilerin analizi sürecinde verilerin geçerlik-güvenirlik çalışmaları için rastgele seçilen iki görüşme metni iki öğretim üyesi ve araştırmacılar tarafından okunarak bu metinlere ilişkin kodlamalar karşılaştırılmış ve tutarsız olan kodlar analiz sürecinden çıkarılmıştır.

\section{Bulgular}

Araştırmanın ana problemi İlahiyat Fakültesi öğrencilerinin nomofobi düzeylerini ölçmek olarak belirlenmiştir. Bu probleme ilişkin elde edilen bulgular nicel ve nitel olmak üzere iki ayrı başlık altında incelenmiştir. 


\section{Ana Probleme İlişkin Nicel Verilerden Elde Edilen Bulgular}

\section{İlahiyat Fakültesi Öğrencilerinin Nomofobi Düzeylerine İlişkin Bul- gular}

Katılımcıların nomofobi düzeyleri ölçekten aldıkları puanlara göre ve aritmetik ortalamaya göre değerledirilmiştir. İlahiyat Fakültesi öğrencilerinin; nomofobi puanları ortalama 69,46 olarak hesaplanmıştır. Araştırmaya katılan öğrencilerin nomofobi düzeylerinin orta olduğu söylenebilir. Katılımcıların nomofobi puanları Tablo 1'de verilmiştir.

Tablo 1: İlahiyat Fakültesi Öğrencilerinin Nomofobi Düzeyleri

\begin{tabular}{lll}
\hline Nomofobi Düzeyi & F & $\%$ \\
\hline Yüksek Düzeyde & 34 & 12,5 \\
Orta Düzeyde & 137 & 49,8 \\
Düşük Düzeye & 104 & 37,7 \\
Toplam & 275 & \\
\hline
\end{tabular}

Katılımcıların aldıkları puanlar değerlendirildiğinde 34 öğrencinin $(\% 12,5)$ düşük düzeyde, $137(\% 49,8)$ öğrencinin orta düzeyde ve 104 $(\% 37,7)$ öğrencinin yüksek düzeyde nomofobi ölçeği toplam puanına sahip olduğu görülmektedir.

\section{İlahiyat Fakültesi Öğrencilerin Nomofobi Ölçeğinin Alt Boyutlarına İlişkin Ortalamaları}

Ölçeğin alt boyutlarına ilişkin ortalama puanlar Tablo 2' de verilmiştir.

Tablo 2: Nomofobi Ölçeğinin alt boyutlarna ilişkin ortalama puanlar

\begin{tabular}{llll}
\hline Alt Boyutlar & Min. & Maks. & Ortalama \\
\hline Bilgiye Erişememe & 1 & 7 & 3.959 \\
Bağlantıyı Kaybetme & 1 & 7 & 3.603 \\
İletişime Geçememe & 1 & 7 & 4.035 \\
Rahat Hissedememe & 1 & 7 & 2.342 \\
Genel & 1 & 7 & 3.488 \\
\hline
\end{tabular}


Ölçek ortalamaları değerlendirildiğinde nomofobi ölçeğinden ortalama alınan puan 3.488 , Bilgiye Erişememe alt boyutunun puan ortalamasının 3.959, Bağlantıyı Kaybetme alt boyutunun puan ortalamasının 3.603, İletişime Geçememe alt boyutunun puan ortalamasının 4.035 ve Rahat Hissedememe alt boyutunun puan ortalamasının 2.342 şeklinde olduğu görülmektedir. İlahiyat Fakültesi öğrencileri en yüksek puanı iletişime geçememe en düşük puanı ise rahat hissedememe alt boyutundan almışlardır.

\section{İlahiyat Fakültesi Öğrencilerinin Nomofobi Düzeyleri ile Cinsiyetleri Arasındaki İlişki}

Katılımcıların cinsiyetleri ile nomofobi düzeyleri arasında anlamlı bir fark olup olmadığına ilişkin bağımsız örneklem t testi sonuçları Tablo 3'te yer almaktadır.

Tablo 3: Cinsiyete Göre Nomofobi Düzeylerine İlişkin t Testi Sonuçları

\begin{tabular}{|c|c|c|c|c|c|c|}
\hline Cinsiyet & $\mathrm{N}$ & & SS & $\mathrm{Sd}$ & $\mathrm{T}$ & $p<$ \\
\hline Kadın & 172 & 3,4930 & 1,18 & 07 & OSO & \\
\hline Erkek & 104 & 3,4830 & 1,13 & $2 / 4$ & ,069 & .001 \\
\hline
\end{tabular}

Tablo 3'te görüldüğü gibi kadınlar ile erkekler arasında nomofobi ortalamaları bakımından anlamlı bir fark bulunmaktadır. Kadın katılımcıların nomofobi ortalamaları $(3,4930)$, erkek katılımcılardan $(3,4830)$ daha yüksektir.

\section{Ana Probleme İlişkin Nitel Verilerden Elde Edilen Bulgular}

\section{Nitel Boyutu:}

Soru 1: Uzun süre telefonunuza bakmadığınızda bir rahatsızlık hisseder misiniz?

Tablo 4: Telefona bakamadığında rahatsızlık hissetme durumuna ilişkin görüşler

\begin{tabular}{lll}
\hline & F & $\%$ \\
\hline Evet & 13 & 76,4 \\
Hayır & 4 & 23,6 \\
\hline
\end{tabular}


Tablo 4 verilerine göre, telefona bakamadığında rahatsızlık hisseden katılımcı oranı $\% 76,4^{\prime}$ tür.

Örnek ifadeler:

"evet rahatsiz oluyorum çünkü hep bir merak içinde oluyorum"

"Evet, bir eksiklik hissederim. Mutlaka bakmam gerektiği hissiyatına kapilırım, yoksa gün boyu aklım kalır"

"Hayır öyle bir rahatsıllık hissetmem. Sebebi çok önemli işlerim ya da kişilerim yok. Aileme ben ulaşırım onlar benimle belirli saatlerde irtibata geçtikleri için diğer vakitlerde hiç bir kaygı hissetmem."

Soru 2: Telefonunuzun şarjının bitmesi sizi rahatsız eder mi?

Tablo 5: Şarjı bittiğinde rahatsızlık hissetme durumuna ilişkin görüşler

\begin{tabular}{lll}
\hline & $\mathrm{f}$ & $\%$ \\
\hline Evet & 14 & 82,4 \\
Hayır & 3 & 17,6 \\
\hline
\end{tabular}

Tablo 5 bulgularından hareketle, katılımclardan $\% 82,4$ 'ü telefonunun şarjı bittiğinde rahatsız olmaktadır.

Örnek İfadeler:

"Evet, telefonum kapanırsa kendimi güvensiz hissederim"

"Evet, kimse bana ulaşamaz diye korkum olmaz ama başıma bir şey gelirse nasil haber ederim diye korkarım."

"Evet. Ani bir durum olduğunda ulaşılamaması korkuttuğu için."

"Evet. Çünkü uzun süre başkalarına ulaşamamak yada bana ulaşılamaması beni rahatsız eder."

Soru 3: İnternet kotanızın ya da tl'lerinizin (kontörünüzün) bitmesi sizi rahatsız eder mi?

Tablo 6: İnternet kotası ya da TL bitmesi bittiğinde rahatsızhk hissetme durumuna ilişkin görü̈şler

\begin{tabular}{lll}
\hline & $\mathrm{f}$ & $\%$ \\
\hline Evet & 13 & 76,4 \\
Hayır & 4 & 23,6 \\
\hline
\end{tabular}


Tablo 6'ya göre, araştırmaya katılan öğrencilerin \%76,4'ü internet kotası dolduğunda ya da bittiğinde rahatsızlık hissetmektedirler.

Örnek ifadeler:

"Evet beni rahatsiz eder. Özellikle internetin bitmesi beni rahatsız eder çünkü o an merak ettiğim veya öğrenmem gereken şeyi öğrenemem."

"Evet. Çünkü tl bittiğinde aileme ulaşamamak beni rahatsız eder. Arkadaşlarımla da genellikle whatshapp üzerinden konuşuruz. Onlardan uzun süre haber almayinca merak ederim."

"Evet rahatsız eder. Çünkü eger tl internet vb şeyler biterse yakın çevremden uzak olduğum için onlara ulaşamam..."

"hayır etmez. Hatta internet kotamin olmaması hoşuma gidiyor daha farklı şeylerle ilgilenme firsatı buluyorum ve aklıma o zaman telefonla uğraşmak dahi gelmiyor. Elimde olunca arryorum interneti yoksa umurumda olmaz."

Soru 4: Ailenize ya da arkadaşlarınıza ulaşamamak sizi rahatsız eder mi?

Tablo 7: Aileye ya da arkadaşlara ulaşamama halinde rahatsızlık hissetme durumuna ilişkin görüşler

\begin{tabular}{lll}
\hline & $\mathrm{f}$ & $\%$ \\
\hline Evet & 16 & 94 \\
Hayır & 1 & 6 \\
\hline
\end{tabular}

Araştırmaya katılan öğrencilerin ailelerine ve arkadaşlarına ulaşamama halinde rahatsızlık hissetme durumları Tablo 7 'de görülmektedir. Nitekim araştırmanın bulguları arasında birilerine ulaşamamadan hissedilen rahatsızlık en yüksek yüzdeye sahip olan bulgudur.

Örnek ifadeler:

"Evet, telefonu asıl kullanış amacım ulaşımdır. Yakınlarıma ulaşamamak beni huzursuz eder"

"Evet çünkü uzaktayım ve ailem benim her şeyim."

"Evet, çünkü onlarla her zaman iletişim halinde olduğum için ulaşamazsam kaygılanırım."

Soru 5: Ailenizin ya da arkadaşlarınızın size hemen ulaşamayacak olması fikri sizi rahatsız eder mi? 
Tablo 8: Aile ya da arkadaşların kendilerine ulaşamama halinde rahatsızlık hissetme durumuna ilişkin görüşler

\begin{tabular}{lll}
\hline & $\mathrm{f}$ & $\%$ \\
\hline Evet & 14 & 82,4 \\
Hayır & 3 & 17,6 \\
\hline
\end{tabular}

Tablo 8 bulgularına göz atıldığında, katılımcıların \%82,4'ü ailelerinin ve arkadaşlarının kendilerine ulaşamadıklarında rahatsız oldukların dile getirmişlerdir.

\section{Örnek ifadeler:}

"Rahatsız eder hocam ilk düşündükleri şey başlarma bir iş mi geldi diye telaşlanirlar"

"Rahatsız eder hocam aksi takdirde ulaşamadıklarında baya bir firça yiyorum"

"Evet, çünkü onları meraklandırmak istemem."

Soru 6: Sosyal medya ya da diğer ağlara istediğiniz anda bağlanamamak sizi rahatsiz eder mi?

Tablo 9: Sosyal ağlara ulaşamama halinde rahatsızhk hissetme durumuna ilişkin görü̈sler

\begin{tabular}{lll}
\hline & $\mathrm{f}$ & $\%$ \\
\hline Evet & 6 & 40 \\
Hayir & 9 & 60 \\
\hline
\end{tabular}

Katılımcların \%60'1 sosyal ağlara ulaşamama durumunda bir rahatsızlık hissetmiyorlar.

\section{Örnek ifadeler:}

"Ĕ̆er gündemi takip ediyorsam rahatsız eder ama onun dışındaki zamanlarda sosyal medya çok önemli değildir benim için"

"Duruma göre değgisir acil durumlarda rahatsız eder keyfi durumlarda etmez"

"hayır, sosyal medyayı anı paylaşmak için kullanıyorum. Bağlanmazsa sonra paylaşırım sıkıntı değil" 
Soru 7: Çevrimiçi olamamak sizi rahatsız eder mi?

Tablo 10: Çevrimiçi olamama halinde rahatsızlık hissetme durumuna ilişkin görüşler

\begin{tabular}{lll}
\hline & $\mathrm{f}$ & $\%$ \\
\hline Evet & 0 & 0 \\
Hayir & 15 & 100 \\
\hline
\end{tabular}

Tablo 10 verilerine göre, katılımcılar, çevrimiçi olmama durumunda rahatsızlık hissetmemektedirler.

Örnek ifadeler:

"hayır, bence insanlar artık sanalda değil reelde çevrimiçi olmalı"

"Yok etmez, çünkü bana ulaşmak isteyen kişi internetten ulaşamıyorsa illaki bir şekilde ulaşır"

"Online olmamak beni rahatsız etmiyor. Uzun süre online olmasam da olur sosyal medya ya bir göz atsam yeterli oluyor benim için."

\section{Tartışma ve Sonuç}

İlahiyat Fakültesi öğrencileri ile gerçekleştirilen bu araştırmanın sonuçlarına göre öğrencilerin nomofobi düzeylerinin orta düzeyde olduğu bulgusuna ulaşılmıştır. Araştırmanın bulgularından öğrencilerin $171(\% 62,3)$ orta ve yüksek yüzeyde, $104(\% 37,7)$ öğrencinin ise düşük düzeyde nomofobiye sahip olduğu görülmektedir. İlahiyat Fakültesi öğrencileri en yüksek skoru iletişime geçememe en düşük skoru ise rahat hissedememe alt boyutundan almışlardır. Kadın katılımcıların nomofobi ortalamaları erkek katılımcılardan daha yüksek olduğu görülmektedir. Sosyal ağ kullanıcılarının nomofobi düzeyinin farklı değişkenlere göre incelendiği Gezgin ve diğ (2017)'lerinin çalışmalarında sosyal ağ kullanıcılarının nomofobi düzeyinin ortalama düzeyde $(X=3,69 ; X=74)$ olduğu tespit edilmiştir. Dolayısıyla Gezgin ve diğerlerinin çalışması, araştırmamızın bulgularını desteklemektedir. Ayrıca, Adnan ve Gezgin (2016) tarafından 433 üniversite öğrencisi üzerinde yapılan çalışmada öğrencilerin nomofobi düzeyleri ortalamanın üzerinde çıkmıştır. 
Akıllı telefonlar iletişim ve kullanım kolaylığı sağlamıştır, fakat sürekli erişilebilme, sık sık telefonunu kontrol etme gibi bazı gereksiz alışkanlıkları da beraberinde getirmiştir. Öğrencilerden telefona bakamadığında rahatsızlık hisseden katılımcı oranı \%76,4 civarındadır, ayrıca katılımcilardan \%82,4'ü telefonunun şarjı bittiğinde rahatsız olmaktadır. Yusufoğlu (2017)'e göre akıllı telefonların insan sağlı̆̆1 üzerinde olumsuz etkileri söz konusudur. Yapılan bu araştırmada örneklem grubunun fiziksel ve ruhsal açıdan akıllı telefonların zararlı etkilerinin farkında oldukları gözlemlenmiştir. Çalışmanın bulguları Yusufoğlu'nun çalışmasını desteklemektedir. Öğrencilerin telefona bakamadıklarında rahatsız olma nedenleri arasında olayları kontrol edememe, durumdan haberdar olamama gibi nedenler gösterilebilir.

Akıllı telefonların yaygınlaşmasıyla birlikte ortaya çıkan davranış sorunlarından bir tanesi de öğrencilerin günlük ve akademik hayatlarında akıllı telefonlarının kullanımının kısıtlandığında ortaya çıkmaktadır. Araştırmaya katılan öğrencilerin $\% 76,4^{\prime}$ ü internet kotası dolduğunda ya da bittiğinde kendilerinde rahatsızlık hissetmektedirler. Araştırmanın bulguları arasında birilerine ulaşamamadan hissedilen rahatsızlık en yüksek yüzdeye sahip olan bulgudur.

Katılımcıların \%82,4'ü ailelerinin ve arkadaşlarının kendilerine ulaşamadıklarında rahatsız oldukların dile getirmişlerdir. Katılımcıların bulgularından çevrimiçi olmadıklarında bir rahatsızlık hissetmedikleri, ama iletişim halinde olmadıklarında ise rahatsız oldukları görülmektedir. Cep telefonları ve akıllı telefonların kullanımı hizla yaygınlaşırken bağımlılık veya huzursuzluk gibi olumsuz etkilerin ortaya çıkmasını da sağlayabilmektedir (Adnan ve Gezgin, 2016).

Nomofobiyi azaltma noktasında ailelere ve öğretmenlere büyük sorumluluklar düşmektedir. Bireylerin farklı etkinliklerle de zaman geçirebileceği konusunda tüm eğitimciler ve aileler bilinçlendirilmelidir. Katılımcıların \%60'ı sosyal ağlara ulaşamama durumunda bir rahatsızlık hissetmemektedir. Araştırmanın bulguları ile Yusufoğlu (2017)'un bulguları sosyal ağlar noktasında bir farklılık göstermektedir. Yusufoğlu (2017)'de, akıllı telefonların en önemli fonksiyonlarından biri olan sosyal medyanın öğrenciler tarafından yaygın olarak kullanıldığını araştırmasında ortaya çıkarmıştır. Aynı araştırmaya göre sırasıyla Whatsapp, Facebook ve Twitter gibi sosyal paylaşım ve iletişim araçları örneklem 
grubu tarafından sıkça kullanılmaktadır. Katılımcılar, çevrimiçi olamama durumundan rahatsızlık hissetmemektedirler.

Akıllı telefon kullanımı öğrencilerin hayatlarında çok dikkat çeken bir düzeye ulaşmıştır. Bu düzey hakkında farklı araştırmalar yapılırken, öğrencinin sık sık telefonunu kontrol etmesi, şarj aletini her zaman yanında bulundurma isteği, sabah uyanır uyanmaz ya da gece yatmadan önce telefonuna bakma isteği, telefonunu gece açık bırakıp sessize alma gibi benzer alışkanlıklar ve davranışlar görülmektedir. Toplum içerisinde giderek artan bir sıklıkla görülen problemli akıllı telefon kullanımı ile ilgili ailelerin ve öğretmenlerin farkındalıklarının arttırılması gerekmektedir. Bu bağlamda öğrencilerin nomofobi düzeylerinin azaltılmasına yönelik olarak okullarda (lise ve üniversite düzeyinde) etkinlikler ve eğitimler düzenlenebilir, siberzorbalık örneğinde olduğu gibi ulusal medya aracılığıyla duyurulacak kamu spotları hazırlanabilir. Bu çalışma, üniversite öğrencileri ile gerçekleştirildiğinden genç yaş grubuna hitap etmektedir. Benzer çalışmalar farklı yaş grupları ile desenlenebilir; bireylerin nomofobi düzeylerinin ve bu düzeylerin etkilendiği değişkenlerin belirlenmesine yönelik farklı örneklemlerle yapılacak nicel ve nitel çalışmalar da alanyazına ayrıca katkı sağlayacaktır. 
EXTENDED ABSTRACT

\title{
The Investigation about Nomofobi Levels of the Students of Theology Faculty in Terms of Various Factors
}

\author{
$*$ \\ E. Zehra Turan - Gökçe Becit İştürk \\ Nevşehir Hacı Bektaş Veli University
}

The advances in information and communication technologies are able to shape our lives negatively as much as positively. The studies in which the prevalence of 'nomophobia' that came out in this context is examined among young people have gained importance. According to the data of Turkey Statistical Institution (TUIK, 2017), it is seen that while the rate of having a portable computer (a laptop, a tablet, a netbook, etc.) at homes was $\% 0,9$ in 2004 , this rose to $\% 49,8$ in 2017 by showing a constant increase in the following years and while the rate of having a mobile/smart phone at homes was $\% 53,7$ in 2004, it increased to $\% 97,8$ in 2017. Telephones which were used to be used only for written-spoken communication at the beginning have transformed into smart phones with its many features such as taking photos, connecting to the internet, communicating and shopping and have become one of the commonly used information and communication technologies. The daily habits of the students of faculty of theology are quite important. Faculty of theology students whose mission to set a good example for the society has often been discussed are likely to use smart phones in their future jobs. The research aims to examine the prevalence of nomophobia which is known as the fear of lack of smart phones among the students of the Faculty of Theology. For this purpose, both qualitative and quantitative data were determined as the sub-aims of the research in order to obtain quantitative data: i) What are the students' nomophobia levels? ii) What are the students' mean scores on the sub-dimensions of the nomophobia scale? iii) Do the students' nomophobia levels differ significantly by gender? In the research, the mixed method including quantitative and qualitative di- 
mensions was used as the analysis technique. Firstly quantitative and then qualitative data were collected in the research. The convergent parallel design out of the mixed designs was used since the quantitative and the qualitative data would be correlated by analyzing them. Qualitative Dimension: The case study among the qualitative research models and the focus group meeting as the survey model were used in the qualitative dimension of the study. Quantitative Dimension: A scale made by Yildirim and Correia (2015) and adapted to Turkish by Yildirim, Shumuer, Adnan and Yildirim (2016) based on the Nomophobia scale (NMPQ) was used as a means of measurement in the study.

For the purpose of the study, the data was collected through a scale made by Yildirim and Correia (2015) and adapted to Turkish by Yildirim, Shumuer, Adnan and Yildirim (2016) based on the Nomophobia scale (NMP-Q), demographic information form and qualitative semistructured interview form. In the quantitative dimension of the study, 276 students were reached.

The measurement tools used in the research were implemented in the spring term of 2017-2018 academic year. 276 students were reached via the convenience sampling method. 172 of the participants are female $(62,3 \%)$ and 104 of them are male $(37,7 \%)$. For the quantitative dimension of the study, 20 of the students who participated in the qualitative dimension of the study were randomly chosen and interviews were conducted.

According to the qualitative research techniques, the scales implemented were coded and analyzed via SPSS 21.0 on the computer. The significance level was determined as .05 in the evaluations.

There have been studies on the nomophobia levels of young age groups especially university students in Turkey and the variables that affect these nomophobia levels. In the study conducted with university students by Adnan and Gezgin (2016), it was seen that the nomophobia levels of the students were over the average.

In the research done by Gezgin, Şumuer, Arslan and Yıldırım (2017), the prevalence of nomophobia among pre-service teachers was examined and it was concluded that the nomophobia levels of pre-service teachers 
were over the average and these pre-service teachers were worried in terms of losing communication and not being able to reach information.

The nomophobia scores of the students of faculty of theology were calculated as 69,46 on average. The nomophobia levels of the students participating in the research can be said to be moderate.

Students of faculty of theology got their highest score in the subdimension that is 'not being able to communicate' and their lowest one in the sub-dimension that is 'not being able to feel comfortable'. There is a significant difference between females and males in terms of their monophobia means. The mean monophobia score of the female participant $(3,4930)$ is higher than that of male participants $(3,4830)$.

The rate of the participants who feel uncomfortable when they do not check their phones is $76,4 \% .82,4 \%$ of the participants get anxious when their batteries run out. $76,4 \%$ of the students who participated in the study feel uneasy when they fill the internet quota.

Feeling anxious because of not being able to communicate with each other is the finding with the highest percentage among the findings of the research.

$82,4 \%$ of the participants stated that they feel anxious when their families or friends cannot reach them.

$60 \%$ of the participants do not feel anxious in case of not being able to reach the social networks. The participants do not feel uncomfortable when they are not online.

It can be seen from the findings that participants do not feel uneasy when they are not online, however, when they are not in contact, they feel uncomfortable. As mobile phone and smart phone use expands rapidly, it may lead to addiction and uneasiness (Adnan and Gezgin, 2016).

Families and teachers have huge responsibilities to decrease nomophobia. All teachers and families should be informed about the fact that individuals can pass the time with various activities. $60 \%$ of the participants do not get anxious in case they cannot reach the social networks.

It is necessary to raise families' and teachers' awareness about the problematic smart phone use that has been observed more and more often in the society. In this context, in order to reduce the nomophobia levels of students, events and trainings can be organized at schools (high school and universities) and public service ads which are going to be 
announced by national media can be prepared as can be seen in 'cyber bullying' example. Since this research was done with university students, it does not appeal to young age groups. Similar studies can be designed with various age groups. Qualitative and quantitative studies which are to be conducted with various samples in order to determine the nomophobia levels of individuals and the variables that affect these levels will also contribute to the literature. It is necessary to know that the same scale must be applied on the students who study in different districts and different departments. It may be needed to conduct further studies about nomophobia and to suggest some solutions to the problems that are possible to arise while making use of the innovations of technology.

\section{Kaynakça/References}

Adnan,M., ve Gezgin,D. M. (2016). Modern çağın yeni fobisi: Üniversite öğrencileri arasında nomofobi prevalansı. Ankara $\ddot{U} n$ iversitesi Ĕ̆itim Fakültesi Dergisi, 49(1), 141-158.

Bragazzi, N.L. ve Pente, G.D. (2014). A proposal for including nomophobia in the new DSM-V. Psychology Research and Behavior Management, 7, 155-160.

Broughton, G. (2015). The changing face [Book] of friendship, fellowship and formation. St Mark's Review, 233, 74-86.

Creswell, J. W. (2008). Educational research planning, conducting and evaluating quantitative and qualitative research. International Pearson Merril Prentice Hall.

Creswell, J. W. ve Plano Clark, V. L. (2015). Karma yöntem araştırmaları: Tasarımı ve yürütülmesi. (Y. Dede, S. B. Demir, Dü, \& A. Delice, Çev.) Ankara, Türkiye: Anı Yayıncılık. 2. Baskı

Fırat, M., Kabakçı Yurdakul, I., ve Ersoy, A. (2014). Bir eğitim teknolojisi araştırmasına dayalı olarak karma yöntem araştırması deneyimi. Journal of Qualitative Research in Education, 2(1), 65-86. doi:10.14689/issn.2148-2624.1.2s3m. 
Gezgin, D.M, Şahin, Y.L. ve Yıldırım Soner, (2017) Sosyal ă̆ kullanıcılarının nomofobi düzeylerinin çeşitli faktörler açısından incelenmesi, Ĕ̆itim Teknolojisi Kuram ve Uygulama, 7(1), 1-15. DOI: 10.17943/etku.288485.

Green, J. C., Krayder, H., ve Mayer, E. (2005). Combining qualitative and quantitative methods in social inquiry. In B. Somekh \& C. Lewin (Eds.). Research methods in the social sciences (pp. 275-282). London: Sage.

Öztürk, U. C. (2015). Bağlantıda kalmak ya da kalmamak işte tüm korku bu: İnternetsiz kalma korkusu ve örgütsel yansımaları. Journal of International Social Research, 8(37), 629-638.

Şar, A. H. ve Işıklar, A. (2012). Adaptation of problem mobile phone use scale to Turkish. Journal of Human Sciences, 9(2), 264-275.

Türnüklü, A. (2000). Eğitim bilim araştırmalarında etkin olarak kullanılabilecek nitel bir araştırma tekniği: Görüşme. Kuram ve Uygulamada Eğitim Yönetimi, 24, 543-559.

Yıldırım, A., ve Şimşek, H. (2008). Sosyal bilimlerde nitel araştırma yöntemleri, 6. Baskı, Ankara: Seçkin Yayıncılık.

Yusufoğlu, Ö.Ş. (2017). Boş zaman faaliyeti olarak akıllı telefonlar ve sosyal yaşam üzerine etkileri: Üniversite öğrencileri üzerine bir araştırma. Insan ve Toplum Bilimleri Araştırmaları Dergisi 6(5), 2414-2434.

\section{Kaynakça Bilgisi / Citation Information}

Turan, E. Z. ve Becit İşçitürk, G. (2018). İlahiyat fakültesi öğrencilerinin nomofobi düzeylerinin çeşitli faktörler açısından incelenmesi. OPUSUluslararası Toplum Araştırmaları Dergisi, 9(16), 1931-1950. DOI: 10.26466/opus. 461523 